\title{
Sensitivity analysis of higher order coherent spectra in machine faults diagnosis
}

DOI:

$10.1177 / 1475921716651394$

\section{Document Version}

Accepted author manuscript

Link to publication record in Manchester Research Explorer

\section{Citation for published version (APA):}

Yunusa-Kaltungo, A., \& Sinha, J. (2016). Sensitivity analysis of higher order coherent spectra in machine faults diagnosis. Structural Health Monitoring, 15(5), 555-567. https://doi.org/10.1177/1475921716651394

\section{Published in:}

Structural Health Monitoring

\section{Citing this paper}

Please note that where the full-text provided on Manchester Research Explorer is the Author Accepted Manuscript or Proof version this may differ from the final Published version. If citing, it is advised that you check and use the publisher's definitive version.

\section{General rights}

Copyright and moral rights for the publications made accessible in the Research Explorer are retained by the authors and/or other copyright owners and it is a condition of accessing publications that users recognise and abide by the legal requirements associated with these rights.

\section{Takedown policy}

If you believe that this document breaches copyright please refer to the University of Manchester's Takedown Procedures [http://man.ac.uk/04Y6Bo] or contact uml.scholarlycommunications@manchester.ac.uk providing relevant details, so we can investigate your claim.

\section{OPEN ACCESS}


Structural Health Monitoring

\section{Sensitivity analysis of higher order coherent spectra in machine faults diagnosis}

\begin{tabular}{|c|c|}
\hline Journal: & Structural Health Monitoring \\
\hline Manuscript ID & SHM-15-0164.R1 \\
\hline Manuscript Type: & Original Manuscript \\
\hline Date Submitted by the Author: & 03-Feb-2016 \\
\hline Complete List of Authors: & $\begin{array}{l}\text { Kaltungo, Akilu; The University of Manchester, School of Mechanical, } \\
\text { Aerospace and Civil Engineering } \\
\text { Sinha, Jyoti; The University of Manchester, MACE }\end{array}$ \\
\hline Keywords: & $\begin{array}{l}\text { Rotating machines, Vibration data fusion, poly coherent composite } \\
\text { bispectrum, poly coherent composite trispectrum , sensitivity analysis }\end{array}$ \\
\hline Abstract: & $\begin{array}{l}\text { In an earlier study, the poly coherent composite higher order spectra (i.e. } \\
\text { poly coherent composite bispectrum and trispectrum) frequency domain } \\
\text { data fusion technique was proposed to detect different rotor related faults. } \\
\text { All earlier vibration-based faults detection (VFD) involving the application } \\
\text { of poly coherent composite bispectrum (pCCB) and trispectrum (pCCT) } \\
\text { have been solely based on the notion that the measured vibration data } \\
\text { from all measurement locations on a rotating machine are always available } \\
\text { and intact. In reality, industrial scenarios sometimes deviate from this } \\
\text { notion, owing to faults and/or damages associated with vibration sensors } \\
\text { or their accessories (e.g. connecting cables). Sensitivity analysis of the } \\
\text { method to various scenarios of measured vibration data availability (i.e. } \\
\text { complete data from all measurement locations and missing/erroneous data } \\
\text { from certain measurement locations) is also examined through } \\
\text { experimental and industrial cases, so as to bring out the robustness of the } \\
\text { method. }\end{array}$ \\
\hline
\end{tabular}

\section{SCHOLARONE}

Manuscripts 


\title{
Sensitivity analysis of higher order coherent spectra in machine faults diagnosis
}

\author{
Akilu Yunusa-Kaltungo and Jyoti K. Sinha* \\ Dynamics Laboratory, School of Mechanical, Aerospace and Civil Engineering, The University of Manchester, Manchester M13 9PL, UK. \\ E-mail addresses: akilu.kaltungo@manchester.ac.uk (A. Yunusa-Kaltungo) and jyoti.sinha@manchester.ac.uk (J.K. Sinha)
}

\begin{abstract}
In an earlier study, the poly coherent composite higher order spectra (i.e. poly coherent composite bispectrum and trispectrum) frequency domain data fusion technique was proposed to detect different rotor related faults. All earlier vibration-based faults detection (VFD) involving the application of poly coherent composite bispectrum (pCCB) and trispectrum ( $\mathrm{pCCT}$ ) have been solely based on the notion that the measured vibration data from all measurement locations on a rotating machine are always available and intact. In reality, industrial scenarios sometimes deviate from this notion, owing to faults and/or damages associated with vibration sensors or their accessories (e.g. connecting cables). Sensitivity analysis of the method to various scenarios of measured vibration data availability (i.e. complete data from all measurement locations and missing/erroneous data from certain measurement locations) is also examined through experimental and industrial cases, so as to bring out the robustness of the method.
\end{abstract}

\section{Keywords}

Rotating machines, induced draft fan, data fusion, poly coherent composite bispectrum, poly coherent composite trispectrum, sensitivity analysis

\footnotetext{
Corresponding author $\left(^{*}\right)$ :

E-mail address: jyoti.sinha@manchester.ac.uk

Tel.: +441613064639.
} 


\section{$1 \quad$ Introduction}

In recent years, several research efforts have been invested into the development of simplified but yet robust vibration-based fault detection (VFD) techniques. One of such VFD approaches is the recently developed poly coherent composite higher order spectra frequency domain data fusion method [1], whereby the dynamic behaviour of a typical rotating machine can be described using a single poly coherent composite bispectrum (pCCB) and/or trispectrum (pCCT), irrespective of the number of vibration data measurement locations on the monitored machine. Based on the results obtained from initially conducted experimental investigations, $\mathrm{pCCB}$ and $\mathrm{pCCT}$ showed that it was possible to significantly reduce the rigour often associated with the computation and analysis of separate higher order spectra (mainly bispectrum and trispectrum) for vibration data collected from individual measurement locations, which can be significant for large industrial rotating machines supported by several bearings (e.g. large industrial turbines or multi-shaft drive assemblies).

Besides the noteworthy ability of using a single $\mathrm{pCCB}$ or $\mathrm{pCCT}$ to effectively distinguish different rotating machine conditions, the recent study conducted by Yunusa-Kaltungo et al. [1] further highlighted the possibilities of developing a hybrid data fusion (i.e. data fusion at both sensor and feature levels) method that can detect and classify different operating conditions in identically configured rotating machines irrespective of their foundation flexibilities and speeds, which may foster the sharing of measured vibration data between identical 'as installed' rotating machines. While it is commendable that enormous research and practical efforts are continuously aimed at improving VFD of rotating machines, it is also well-known that the successful operation of any VFD system is a direct function of the proper integration of its 3 fundamental stages, namely; data collection, signal processing and fault diagnosis. The data collection stage of a typical VFD system provides the vibration data from which features (e.g. kurtosis, peak-to-peak amplitude, 1x, 2x, 3x, etc.) are extracted during 
signal processing, before eventually matching the various identified features with corresponding machine conditions during fault diagnosis. The adverse conditions under which most industrial rotating machines operate as well as the fragility of VFD instruments sometimes restrict the availability of measured vibration data, which often affects the effectiveness of the entire VFD system.

Until now, studies on VFD of rotating machines have been significantly based on the premise that vibration data from all sensors are intact and available, irrespective of whether the measured vibration data will be separately analysed for individual measurement locations with known techniques such as spectrum analysis [2-7], wavelet analysis [8-15], higher order statistical analysis [16-23], etc., or fused together for all measurement locations to generate a single but representative poly coherent composite spectrum [1]. In practise, the amount of data available for faults diagnosis of some rotating machines may be limited at certain instances, owing to faults/damages associated with the sensors or connecting cables during auxiliary activities in the plant such as machine cleaning or general maintenance, especially when dealing with critical industrial rotating machines that are installed in highly remote and/or restricted plant locations (e.g. river gallery pumps in water generation plants or drilling machines in mines). Such damages usually lead to the loss of vibration data from certain measurement locations on these critical rotating machines.

Often the operational demands as well as extremely low tolerances for equipment downtime in most industrial plants, the VFD analyst may be sometimes confined to conducting faults diagnosis based on limited measured vibration data, as it may not be always feasible to recollect the vibration data representing the behaviours of such critical industrial rotating machines. Based on this premise, it will be very useful to develop a VFD technique that possesses the capability to identify incipient changes in the operating conditions of a rotating 
machine due to the emergence of different faults, despite the unavailability of measured vibration data from certain measurement locations on the machine.

In the current study, the concepts of $\mathrm{pCCB}$ and $\mathrm{pCCT}$ are applied to two examples laboratory scale experimental rig and critical cement manufacturing process fan. During both experiments, vibration measurements were obtained from all the four bearing locations while considerations were also given to practical instances whereby some of the measurements acquired from some sensors may be faulty. However, timely machine fault diagnosis is often a requirement for all plants, irrespective of the completeness of the measured data. In the current study, measured vibration data under different scenarios of data availability are analysed with the method so as to understand its sensitivity and robustness in faults classification for both examples, which generally leads to faults diagnosis. Hence, the current paper explains;

- The computational concepts of pCCB and pCCT.

- The experimental and industrial examples considered.

- The laboratory experiments conducted as well as on-site measurements in the cement plant.

- The data analysis, especially the sensitivity analysis for faults classification based on both experimental and industrial examples.

\section{Computation of poly Coherent Composite Spectra}

Equations (1)-(3) respectively provide the mathematical computations of the poly Coherent Composite Spectra for an entire rotating machine with "b" number of vibration measurement 
locations, which has already been extensively described in an earlier study by YunusaKaltungo et al. [24, 1$]$.

$$
\begin{gathered}
\mathrm{S}_{\mathrm{pCCS}}\left(f_{\mathrm{k}}\right)=\left(\frac{\sum_{\mathrm{r}=1}^{\mathrm{n}_{\mathrm{s}}} \mathrm{X}_{1}^{\mathrm{r}}\left(f_{\mathrm{k}}\right) \mathrm{Y}_{12}^{2} \mathrm{X}_{2}^{\mathrm{r}}\left(f_{\mathrm{k}}\right) \mathrm{Y}_{23}^{2} \mathrm{X}_{3}^{\mathrm{r}}\left(f_{\mathrm{k}}\right) \mathrm{Y}_{34}^{2} \mathrm{X}_{4}^{\mathrm{r}}\left(f_{\mathrm{k}}\right) \ldots \mathrm{x}_{(\mathrm{b}-1)}^{\mathrm{r}}\left(f_{\mathrm{k}}\right) \mathrm{Y}_{(\mathrm{b}-1) \mathrm{b}}^{2} \mathrm{X}_{\mathrm{b}}^{\mathrm{r}}\left(f_{\mathrm{k}}\right)}{\mathrm{n}_{\mathrm{s}}}\right)(1 / \mathrm{b}) \\
\mathrm{B}\left(f_{\mathrm{l}}, f_{\mathrm{m}}\right)=\frac{\sum_{\mathrm{r}=1}^{\mathrm{n}_{\mathrm{s}}}\left(\mathrm{X}_{\mathrm{pCCS}}^{\mathrm{r}}\left(f_{1}\right) \mathrm{X}_{\mathrm{pCCS}}^{\mathrm{r}}\left(f_{\mathrm{m}}\right) \mathrm{X}_{\mathrm{pCCS}}^{\mathrm{r}^{*}}\left(f_{1}+f_{\mathrm{m}}\right)\right)}{\mathrm{n}_{\mathrm{s}}} \\
\mathrm{T}\left(f_{\mathrm{l}}, f_{\mathrm{m}}, f_{\mathrm{n}}\right)=\frac{\sum_{\mathrm{r}=1}^{\mathrm{n}_{\mathrm{s}}}\left(\mathrm{X}_{\mathrm{pCCS}}^{\mathrm{r}}\left(f_{\mathrm{l}}\right) \mathrm{X}_{\mathrm{pCCS}}^{\mathrm{r}}\left(f_{\mathrm{m}}\right) \mathrm{X}_{\mathrm{pCCS}}^{\mathrm{r}}\left(f_{\mathrm{n}}\right) \mathrm{X}_{\mathrm{pCCS}}^{\mathrm{r}^{*}}\left(f_{1}+f_{\mathrm{m}}+f_{\mathrm{n}}\right)\right)}{\mathrm{n}_{\mathrm{s}}}
\end{gathered}
$$

In Equation (1), $\mathrm{X}_{1}^{\mathrm{r}}\left(f_{\mathrm{k}}\right), \mathrm{X}_{2}^{\mathrm{r}}\left(f_{\mathrm{k}}\right), \mathrm{X}_{3}^{\mathrm{r}}\left(f_{\mathrm{k}}\right), \mathrm{X}_{4}^{\mathrm{r}}\left(f_{\mathrm{k}}\right), \ldots, \mathrm{X}_{(\mathrm{b}-1)}^{\mathrm{r}}\left(f_{\mathrm{k}}\right)$ and $\mathrm{X}_{\mathrm{b}}^{\mathrm{r}}\left(f_{\mathrm{k}}\right)$ respectively denote the Fourier transformation (FT) of the rth segment at frequency $f_{\mathrm{k}}$ of the vibration responses at bearings $1,2,3,4, \ldots .,(b-1)$ and $b$. Similarly, $\gamma_{12}^{2}, \gamma_{23}^{2}, \gamma_{34}^{2}, \ldots ., \gamma_{(b-1) b}^{2}$ respectively denote the coherence [25] between bearings $1-2,2-3,3-4, \ldots,(b-1)-b . S_{p C C S}\left(f_{\mathrm{k}}\right)$ is the poly-Coherent Composite Spectrum (pCCS) at frequency, $f_{\mathrm{k}}$.

The $\mathrm{X}_{\mathrm{pCCS}}^{\mathrm{r}}$ shown in Equations (2)-(3) represents the poly coherent composite FT for a particular segment ' $r$ ' of the measured vibration data from ' $b$ ' bearing locations at a particular frequency, $f_{\mathrm{k}}$, which was also computed as [24];

$$
\left.\mathrm{X}_{\mathrm{pCCS}}^{\mathrm{r}}\left(f_{\mathrm{k}}\right)=\left(\mathrm{X}_{1}^{\mathrm{r}}\left(f_{\mathrm{k}}\right) \gamma_{12}^{2} \mathrm{X}_{2}^{\mathrm{r}}\left(f_{\mathrm{k}}\right) \gamma_{23}^{2} \mathrm{X}_{3}^{\mathrm{r}}\left(f_{\mathrm{k}}\right) \gamma_{34}^{2} \mathrm{X}_{4}^{\mathrm{r}}\left(f_{\mathrm{k}}\right) \ldots \mathrm{X}_{(\mathrm{b}-1)}^{\mathrm{r}}\left(f_{\mathrm{k}}\right) \gamma_{(\mathrm{b}-1) \mathrm{b}}^{2} \mathrm{X}_{\mathrm{b}}^{\mathrm{r}}\left(f_{\mathrm{k}}\right)\right)^{(1 / \mathrm{b}}\right)
$$


In order to enhance proper understanding of the current study, a brief re-iteration of the steps involved in the computations of pCCB and pCCT VFD method are again illustrated by the flowchart shown in Figure 1.

\section{$3 \quad$ Example 1: Laboratory Scale Experimental Rig}

The laboratory scale experimental rig consists of two rigidly coupled shafts (S1 and S2) and three identical balance discs (D1, D2 and D3). D1 and D2 are mounted on S1, while D3 is mounted on S2. S1 was then flexibly coupled (FC) to an electric motor (EM), and the complete rig assembly is supported by four bearings (B1-B4). Figure 2 shows a photograph of the experimental rig, while Table 1 provides the specifications of its main components. On this experimental rig [1], the five experimentally simulated cases (C1-C5) detailed in Table 2 were studied at a machine speed of 1800 RPM (30 Hz). Under each case, 20 sets of vibration measurements were collected through the aid of 4 accelerometers (A1-A4).

\subsection{Earlier Faults detection method [1]}

The earlier study conducted by Yunusa-Kaltungo et al. [1] has already provided significant details about the capabilities of the method to detect several rotor related faults at different machine speeds. Despite the earlier [1] investigations, it is anticipated that a brief recap of the earlier observations will significantly buttress the understanding and relevance of the current study. Using $\mathrm{C} 1$ and $\mathrm{C} 2$ cases as illustration, the signal processing parameters in Table 3 were used to compute $\mathrm{pCCB}$ and $\mathrm{pCCT}$ for a set of measured vibration data. It is clearly visible from Figure 3 that the pCCB features for both cases are significantly different. For instance, the $\mathrm{C} 1$ case (Figure 3(a)) contained a slightly prominent $\mathrm{B}_{11}$ pCCB peak and very negligible $B_{12}=B_{21}$ and $B_{22}$ peaks while the $C 2$ (Figure 3(b)) case contained several pCCB 
components $\left(\mathrm{B}_{11}, \mathrm{~B}_{12}=\mathrm{B}_{21}, \mathrm{~B}_{22}, \mathrm{~B}_{13}=\mathrm{B}_{31}\right.$ and $\left.\mathrm{B}_{23}=\mathrm{B}_{32}\right)$ with significantly larger amplitudes. Similarly, the computed pCCT features (Figure 4) for $\mathrm{C} 1$ and $\mathrm{C} 2$ cases are very different. The C1 case (Figure 4(a)) contains only $\mathrm{T}_{111}$ pCCT component. As observed with pCCB (Figure 3), the C2 case (Figure 4(b)) contained several pCCT components $\left(\mathrm{T}_{112}=\mathrm{T}_{121}=\mathrm{T}_{211}\right.$, $\mathrm{T}_{122}=\mathrm{T}_{212}=\mathrm{T}_{221}, \mathrm{~T}_{222}, \mathrm{~T}_{113}=\mathrm{T}_{131}=\mathrm{T}_{311}$ and $\left.\mathrm{T}_{333}\right)$.

Figures 3-4 clearly indicate the capabilities of $\mathrm{pCCB}$ and $\mathrm{pCCT}$ plots to provide distinctions between different machine conditions. The earlier study by Yunusa-Kaltungo et al. [1] proposed the combination of the amplitudes of $\mathrm{pCCB}$ and $\mathrm{pCCT}$, owing to the rigour and subjectivities associated with limiting faults detection to visual inspection of numerous and sometimes highly diverse $\mathrm{pCCB}$ and $\mathrm{pCCT}$ components that emerge as a result of continuous measurement and analysis of vibration data during routine condition monitoring (CM) activities. Hence, Figure 5 again shows the benefits of such a combined approach based on using 20 sets of measured vibration data for each experimentally simulated case. It is visible from Figure 5 that data related to each case are clustered together and separated from the clusters of other cases.

\section{$4 \quad$ Sensitivity Analysis based on Laboratory Experimental Data}

In Figure 5, the faults classification based on the combination of the computed $\mathrm{B}_{11} \mathrm{pCCB}$ and $\mathrm{T}_{111}$ pCCT components for all 100 sets (i.e. 20 sets of data per case) of measured vibration data for $\mathrm{C} 1-\mathrm{C} 5$ cases solely assumes an ideal laboratory scenario $\left(\mathrm{LS}_{0}\right)$, where the data from all four measurement locations are available and intact. However, this scenario may not always be practicable in "real life" industrial machines, owing to the possibilities of damages 
to sensors or their accessories at certain instances. In order to ascertain the robustness and sensitivity of this technique under changing conditions of measured vibration data availability, the four additional scenarios $\left(\mathrm{LS}_{1}-\mathrm{LS}_{4}\right)$ described in Table 4 have been considered. In all four scenarios, vibration data from only three measurement locations were used to compute the $\mathrm{pCCB}$ and $\mathrm{pCCT}$ components that produced the faults classifications shown in Figure 6. Based on the current experimental rig and cases simulated, the omission of measured vibration data from certain measurement locations did not have any significant effect on the faults classification patterns. In fact, Figure 6 shows that data corresponding to each of the five experimentally simulated cases consistently remained clustered together and separated from the clusters of other cases under all scenarios of data availability. For all scenarios, the $\mathrm{C} 2$ cluster consistently occupied the highest position owing to its possession of significantly greater $\mathrm{B}_{11}$ pCCB and $\mathrm{T}_{111}$ pCCT components amplitudes. $\mathrm{C} 1, \mathrm{C} 4$ and $\mathrm{C} 5$ cases for all scenarios possessed relatively similar $\mathrm{T}_{111}$ pCCT components amplitudes, but the variations in their $\mathrm{B}_{11} \mathrm{pCCB}$ components amplitudes still enabled appreciable separations between them which further highlight the benefits of faults detection based on the combination of $\mathrm{pCCB}$ and $\mathrm{pCCT}$ components. Similarly, the cluster comprising of data related to the $\mathrm{C} 3$ case was positioned at the bottom left corner of the plots for all scenarios due to its lower $\mathrm{B}_{11} \mathrm{pCCB}$ and $\mathrm{T}_{111} \mathrm{pCCT}$ components amplitudes.

In order to perform a more detailed examination of the consistency of the clustering for individual cases under all the scenarios described in Table $4, \mathrm{~B}_{11} \mathrm{pCCB}$ and $\mathrm{T}_{111} \mathrm{pCCT}$ components amplitudes were then separately combined for each experimentally simulated case for all scenarios (for example $\mathrm{C} 1$ for $\mathrm{LS}_{0}-\mathrm{LS}_{5}$ and so on). The results of the various combinations are shown in Figure 7, where it was again observed that the clusters for individual cases for all the considered scenarios appear around the same region. For instance, 
Figure 7(a)-(e) respectively show the clustering together of C1-C5 cases for scenarios $\mathrm{LS}_{0^{-}}$ $\mathrm{LS}_{4}$. It is also interesting to note that the patterns and relative locations of the clusters for the four scenarios representing missing data (i.e. $\mathrm{LS}_{1}-\mathrm{LS}_{4}$ ) cannot be distinguished from that of the ideal scenario $\left(\mathrm{LS}_{0}\right)$. Therefore, based on the current experimental data and scenarios considered, the combined $\mathrm{pCCB}$ and pCCT VFD technique is robust enough to classify rotating machine faults despite the unavailability of data from certain measurement locations.

\section{$5 \quad$ Example 2: Industrial Fan}

A fundamental rationale behind the development of any new rotating machines VFD technique (or any other technique) is usually to enhance and/or simplify the currently existing faults detection process in "real life" industrial machines. Based on this premise, the current study similarly explored the capability and robustness of pCCB and pCCT [1] in detecting changes in the operating conditions of a very critical cement process rotary kiln induced draft fan (RKIDF), due to the emergence of fault(s).

\subsection{The Case Study (RKIDF)}

The case study is a rotary kiln ID fan (RKIDF) for a cement process plant (Figure 8), which its main technical specifications are shown in Table 5. The RKIDF is a twin inlet backward curved centrifugal fan that provides air draft across the cement rotary kiln. The entire fan assembly is supported by four bearings, namely; motor drive end (MDE), motor non-drive end (MNDE), fan drive end (FDE) and fan non-drive end (FNDE) bearings as shown in Figure 8 . The motor and fan shafts are coupled by a very flexible spring-type coupling. 
The RKIDF performs two very critical functions in the cement manufacturing process. Firstly, the draft of air needed for fuel combustion during clinker (the main component of cement) production is provided by the RKIDF. Secondly, the hot kiln exit gases used for drying and pre-heating fresh kiln feed are also conveyed by the RKIDF. In order to increase the rotary kiln throughput, there has to be a corresponding increase in the amount of fuel to be burnt, which is directly dependent on the RKIDF speed (i.e. higher kiln feed requires more fuel; more fuel requires more combustion air and more combustion air requires higher RKIDF speed and vice versa). Since the performance of cement process plants is most often judged by the outputs from their rotary kilns (since this stage produces the clinker that is eventually grinded into cement in the cement mills), the optimum performance and reliability of the RKIDF is very vital. The criticality of RKIDF to this cement burning line is further compounded by its lack of built-in redundancy (i.e. no standby available), as illustrated by Figure 9.

\subsection{On-site Vibration Measurements}

During the on-site measurements, a total of 40 sets of vibration data were collected from the RKIDF assembly at $600 \mathrm{RPM}(10 \mathrm{~Hz})$ fan speed. The first 20 sets of vibration data were collected during the RKIDF faulty condition, while the other 20 sets of vibration data were collected immediately after the conduction of a corrective maintenance intervention to align the machine and remove heavy limestone deposits from the impeller blades (Figure 10). During these measurements (Figure 11), 4 diagonally mounted accelerometers (one per bearing) were used for collecting vibration data at a sampling frequency $\left(f_{\mathrm{s}}\right)$ of $10000 \mathrm{~Hz}$ onto a PC, through the aid of a sixteen channels 16-bit analogue-to-digital converter (ADC), as 
shown in Figure 11. In Figure 11, PC, ADC and A1-A4 respectively denote personal computer, analogue-to-digital converter and accelerometers 1-4.

\subsection{Detection and classification of RKIDF operating conditions using earlier method}

As performed with the experimentally acquired data, (Section 3.1), the earlier method was also used to analyse one set of vibration data measured on the RKIDF under faulty and healthy conditions. As anticipated, Figures 12-13 respectively display distinct pCCB and pCCT faults diagnosis for both cases. The faulty case (Figure 12(a)) contains a very dominant $\mathrm{B}_{11}$ pCCB peak along with smaller $\mathrm{B}_{12}=\mathrm{B}_{21}$ and $\mathrm{B}_{13}=\mathrm{B}_{31}$ pCCB peaks, while the healthy case (Figure 12(b)) only contained very negligible $\mathrm{B}_{11}$ and $\mathrm{B}_{12}=\mathrm{B}_{21}$ pCCB components. Similarly, the pCCT components shown in Figure 13 are different for both RKIDF cases. The healthy case (Figure 13(b)) contained a single $\mathrm{T}_{111}$ pCCT component, while the faulty case (Figure 13(a)) contained several pCCT components $\left(\mathrm{T}_{112}=\mathrm{T}_{121}=\mathrm{T}_{211}\right.$ and $\left.\mathrm{T}_{113}=\mathrm{T}_{131}=\mathrm{T}_{311}\right)$ in addition to a large $\mathrm{T}_{111} \mathrm{pCCT}$ component.

Similarly, the combined amplitude approach described earlier [1] was also explored for the classification of 40 sets (i.e. 20 sets for faulty and 20 sets for healthy cases) of vibration data acquired from the RKIDF, where it is again visible from Figure 14 that all data sets related to the faulty case are grouped in the same cluster and separated from the cluster comprising of data sets measured during the healthy RKIDF condition.

\section{$6 \quad$ Sensitivity Analysis based on Industrial Experimental Data}

The faults classification shown in Figure 14 is based on an ideal industrial scenario $\left(\mathrm{IS}_{0}\right.$ ) of total data availability from all measurement locations, which might not always be the case. 
Hence, four additional industrial scenarios $\left(\mathrm{IS}_{1}-\mathrm{IS}_{4}\right)$ similar to those described in Table 4 have also been considered with the industrial experimental data, and the result of the faults classification for each scenario is shown in Figures 15(a)-(d). As observed in the laboratory experimental example (Section 4), the healthy and faulty conditions were separately clustered for all scenarios (Figure 15), which might be an indication of the industrial applicability of the technique in the near future.

Figures 16(a)-(b) respectively show the separate combination of all faulty and healthy data for the different scenarios $\left(\mathrm{IS}_{1}-\mathrm{IS}_{4}\right)$ listed in Table 3, including the ideal scenario of complete measured vibration data from all measurement locations $\left(\mathrm{IS}_{0}\right)$. The observations were quite similar and consistent with the laboratory experimental example, with the clusters relating to each of the machine conditions from all scenarios retaining their unique and respective regions.

\section{$7 \quad$ Concluding Remarks}

The quantity of measured vibration data available for classifying an industrial rotating machine as healthy or faulty could be sometimes hampered by damages to VFD sensors during routine field activities such as machine cleaning and general maintenance. The avenues for ensuring the integrity of installed VFD sensors such as accelerometers prior to each instance of data acquisition is sometimes restricted by the immense production requirements, especially when dealing with an on-line condition monitoring system for critical rotating machines situated in isolated plant locations. Based on this premise, faults classification of rotating machines (which generally leads to faults diagnosis) may be performed based on the available vibration data from only certain measurement locations. In 
the current study, several sets of measured vibration data from an experimental rig and a critical induced draft fan of a cement manufacturing company have been collected under different operating conditions. The results of the faults classification performed using a combination of the amplitudes of poly coherent composite bispectrum and trispectrum components for different scenarios of measured vibration data (i.e. complete and incomplete data), indicated that the proposed technique is able to separately classify the different cases. This highlights the robustness and insensitivity of the technique to variations in the availability of measured vibration data, which may be very useful for faults identification in critical industrial rotating machines, especially those installed in remote and isolated locations, where the frequency of machine inspection is very low. Future considerations for the current study will be aimed at observing other classes of rotating machine faults (e.g. bearing and gear faults) as well as the impacts of their severities on the cluster patterns.

\section{$8 \quad$ Acknowledgement}

Akilu Yunusa-Kaltungo would like to extend his profound gratitude to the plant manager (Mr. Graeme Bride) and the entire manufacturing team of Lafarge Cement PLC (Ashaka plant), for granting the permission to acquire and publish the vibration data and equipment technical specifications used for this study.

\section{References}

[1] Yunusa-Kaltungo A, Sinha JK and Nembhard AD. A novel faults diagnosis technique for enhancing maintenance and reliability of rotating machines. Structural Health Monitoring 2015 (in press); pp 1-18. DOI: 10.1177/1475921715604388

[2] Goldman P and Muszynska A. Application of full spectrum to rotating machinery diagnosis. Orbit 1999; first quarter. 
[3] Deng L and Zhao R. A vibration analysis method based on hybrid techniques and its application to rotating machinery. Measurement 2013; 46: 3671-3682.

[4] Fengqi W and Meng G. Compound rub malfunctions feature extraction based on fullspectrum cascade analysis and SVM. Mechanical Systems and Signal Processing 2006; 20(8): 2007-2021.

[5] Muruganatham B, Sanjith MA, Krishnakumar B, et al. Roller element bearing fault diagnosis using singular spectrum analysis. Mechanical Systems and Signal Processing 2013; 35(1): 150-166.

[6] Bouleux G. Oblique projection pro-processing and TLS application for diagnosing rotor bar defects by improving power spectrum estimation. Mechanical Systems and Signal Processing 2013; 41(1): 301-312.

[7] Yunusa-Kaltungo A, Nembhard AD and Sinha JK. Experimental observations of rotor orbits analysis in rotating machines. Proceedings of 9th IFToMM International Conference on Rotor Dynamics (IFToMM ICORD 2014), Milan, Italy, September 22252014.

[8] Li P, Kong F, He Q, et al. Multiscale slope feature extraction for rotating machinery fault diagnosis using wavelet analysis. Measurement 2013; 46(1): 497-505.

[9] Muralidharan V and Sugumaran V. Feature extraction using wavelets and classification through decision tree algorithm for fault diagnosis of mono-block centrifugal pump. Measurement 2013; 46(1): 353-359.

[10] Jian H, Li C and Li H. An improved EEMD with multiwavelet packet for rotating machinery multi-fault diagnosis. Mechanical Systems and Signal Processing 2013; 36(2): 225-239.

[11] Yan R, Gao RX and Chen X. Wavelets for faults diagnosis of rotating machines: a review with applications. Signal Processing 2014; 96: 1-15.

[12] Luo GY, Osypiw D and Irle M. On-line vibration analysis with fast continuous wavelet algorithm for condition monitoring of bearing. Journal of Vibration and Control 2003; 9(8): 931-947.

[13] Ziaja A, Antoniadou I, Barszcz T, et al. (2014) Fault detection in rolling element bearings using wavelet-based variance analysis and novelty detection. Journal of Vibration and Control 2014; 1-16 (accessed on 15 February 2015, DOI: 1077546314532859).

[14] Sun W, Yang GA, Chen Q, et al. Fault diagnosis of rolling bearing based on wavelet transform and envelope spectrum correlation. Journal of Vibration and Control 2012; 19(6): 924-941. 
[15] Liu J, Wang W and Ma F. Bearing system health condition monitoring using a wavelet cross-spectrum analysis technique. Journal of Vibration and Control 2012; 18(7): 953-963.

[16] Collis WB, White PR and Hammond JK. Higher-order spectra: The bispectrum and trispectrum. Mechanical Systems and Signal Processing 1998; 12(3): 375-394.

[17] Fackrell JWA, White PR, Hammond JK, et al. The interpretation of the bispectra of vibration signals-II: Experimental results and applications. Mechanical Systems and Signal Processing 1995; 9(3): 267-274.

[18] Yunusa-Kaltungo A and Sinha JK. Combined bispectrum and trispectrum for faults diagnosis in rotating machines. Proceedings of the Institution of Mechanical Engineers, Part O: Journal of Risk and Reliability 2014; 228: 419-428.

[19] Sinha JK. Higher order spectra for crack and misalignment identification in the shaft of a rotating machine. Structural Health Monitoring 2007; 6(4): 325-334.

[20] Jiang L, Liu Y, Li X, et al. Using bispectral distribution as a feature for rotating machinery fault diagnosis. Measurement 2011; 44(7): 1284-1292.

[21] Wang $\mathrm{H}$ and Chen J. Performance degradation assessment of rolling bearing based on bispectrum and support vector data description. Journal of Vibration and Control 2014; 20(13): 2032-2041.

[22] Yunusa-Kaltungo A and Sinha JK. A comparison of signal processing tools: Higher order spectra versus higher order coherences. Journal of Vibration Engineering \& Technologies 2015; 3(4): 461-472.

[23] Yunusa-Kaltungo A, Sinha JK and Nembhard AD. Use of composite higher order spectra for faults diagnosis of rotating machines with different foundation flexibilities. Measurement 2015; 70: 47-61.

[24] Yunusa-Kaltungo A, Sinha JK and Elbhbah K. An improved data fusion technique for faults diagnosis in rotating machines. Measurement 2014; 58: 27-32.

[25] Suryam BCBN, Meher KK, Sinha JK and Rao AR. Coherence measurement for early contact detection between two components. Journal of Sound and Vibration 2006; 290(1): 519-523.

[26] Howden (2010) Lafarge Cement PLC (Ashaka Plant) GEPOL fan line 1 operation and maintenance manual (Type: L3N 2176.12.79 DBL6T, Ref: 10 VR 059).

[27] Yunusa-Kaltungo and Sinha JK. First aid treatment for machine vibration problems. Maintenance Engineering and Asset Management Journal 2014; 29(2): 49-50. 
List of Figures

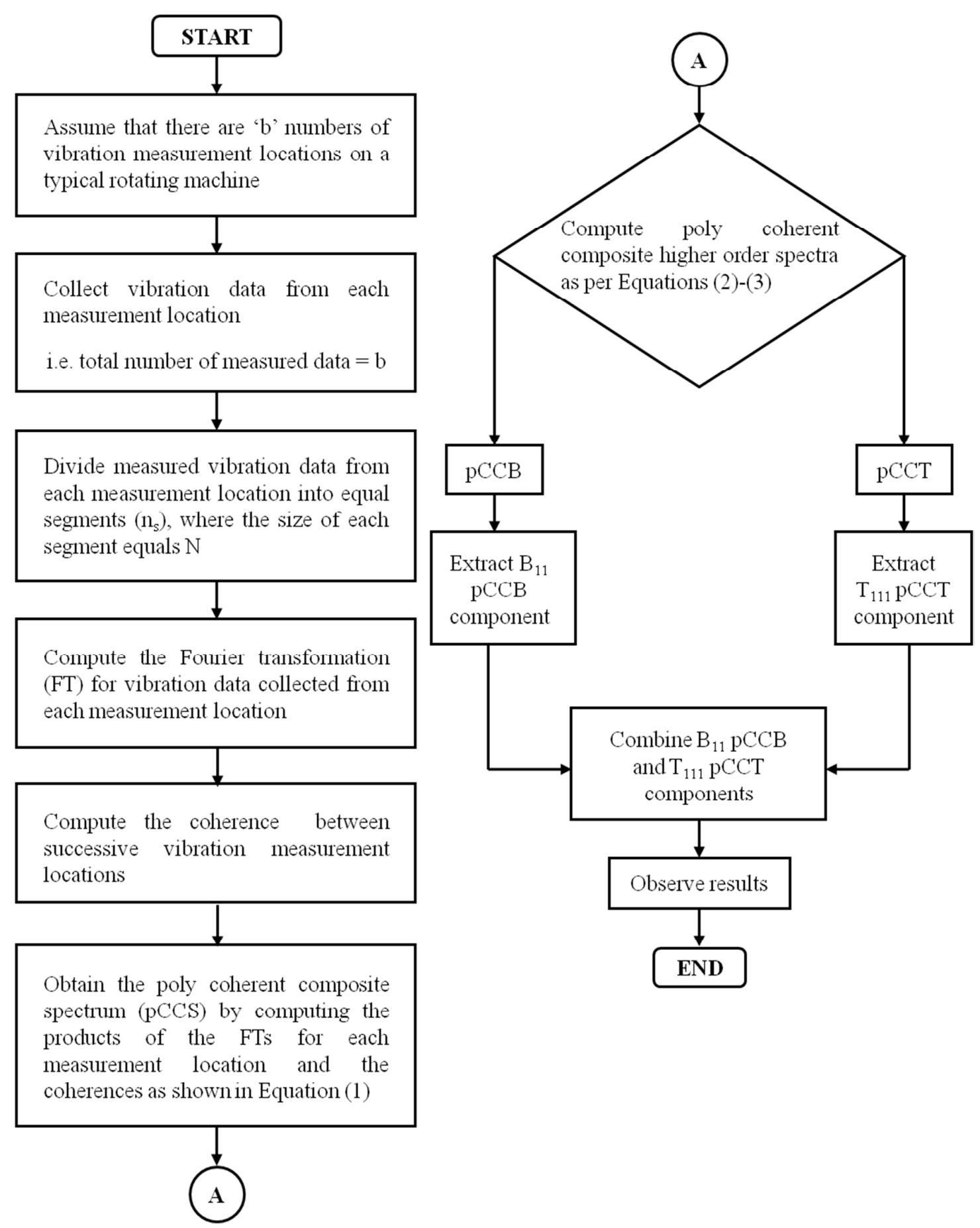

Figure 1 poly coherent composite spectra computational process flowchart 


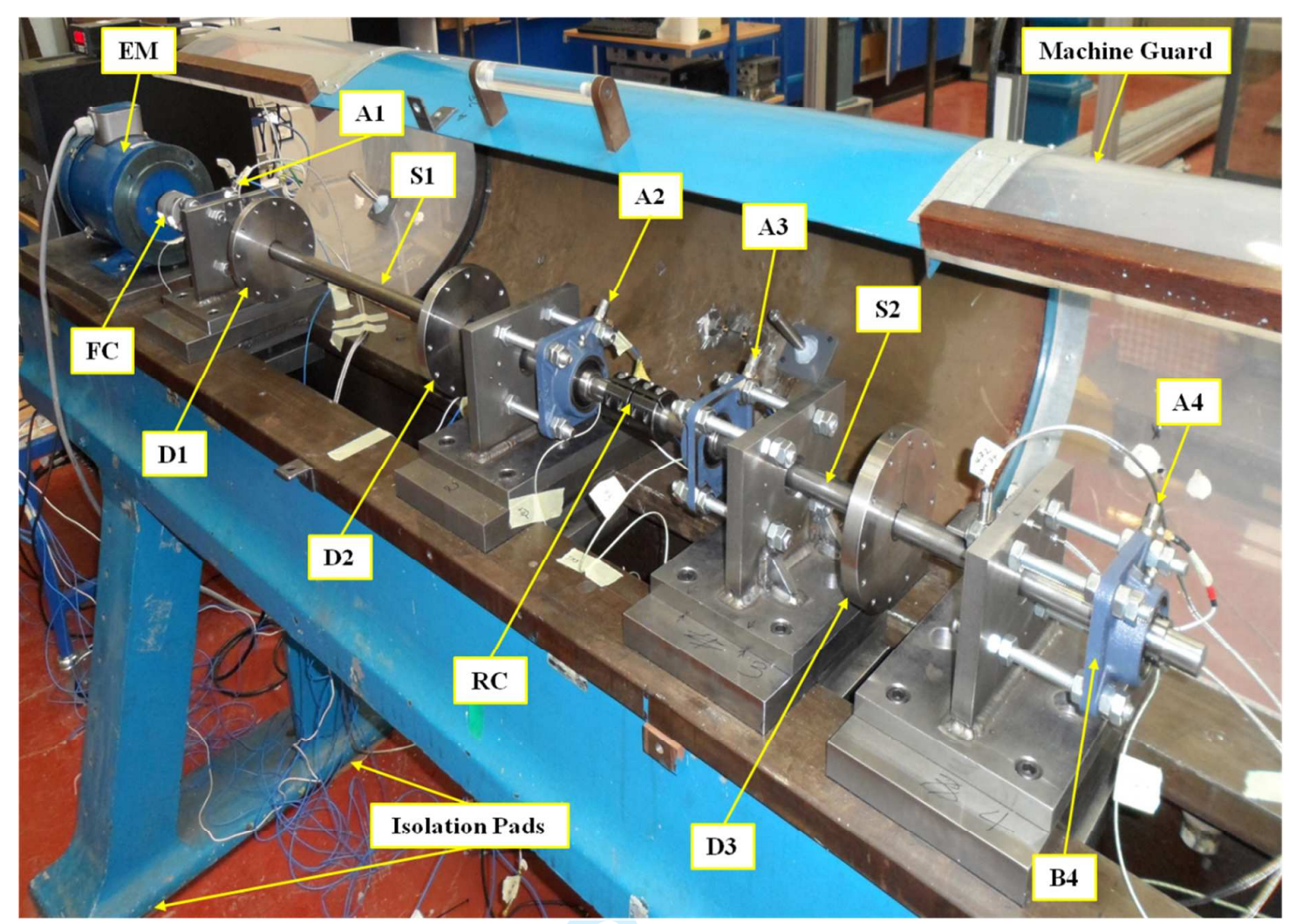

Figure 2 Laboratory scale experimental rig [1] 

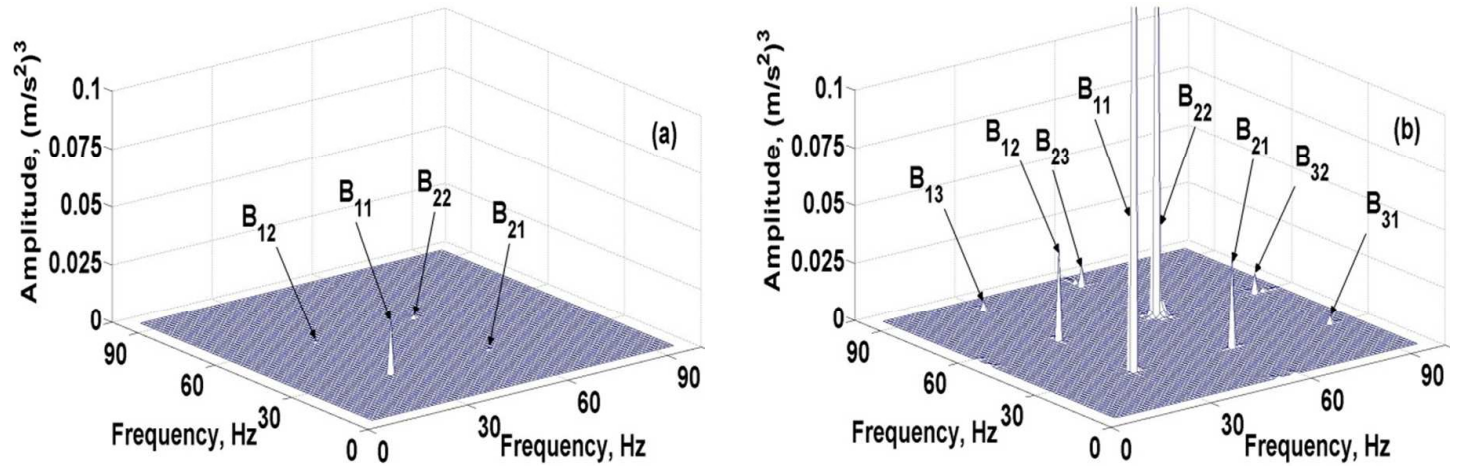

Figure 3 Typical pCCB plots (a) $\mathrm{C} 1$ (b) $\mathrm{C} 2$ 
1

2

3

4

5

6

7

8

9

10

11

12

13

14

15

16

17

18

19

20

21

22

23

24

25

26

27

28

29

30

31

32

33

34

35

36

37

38

39

40

41

42

43

44

45

46

47

48

49

50

51

52

53

54

55

56

57

58

59

60
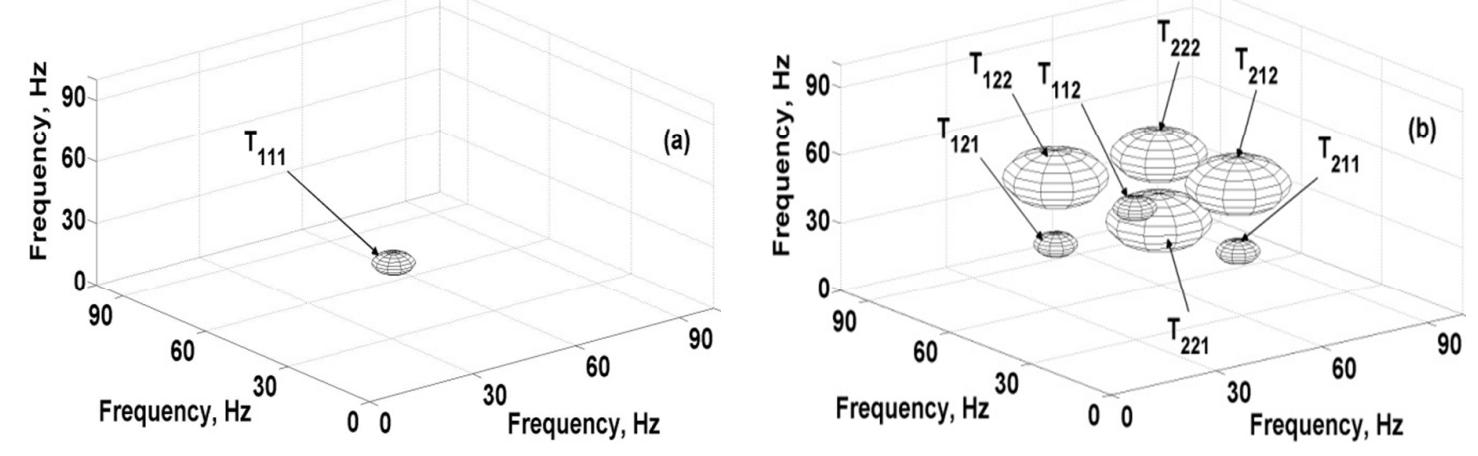

Figure 4 Typical pCCT plots (a) C1 (b) C2 


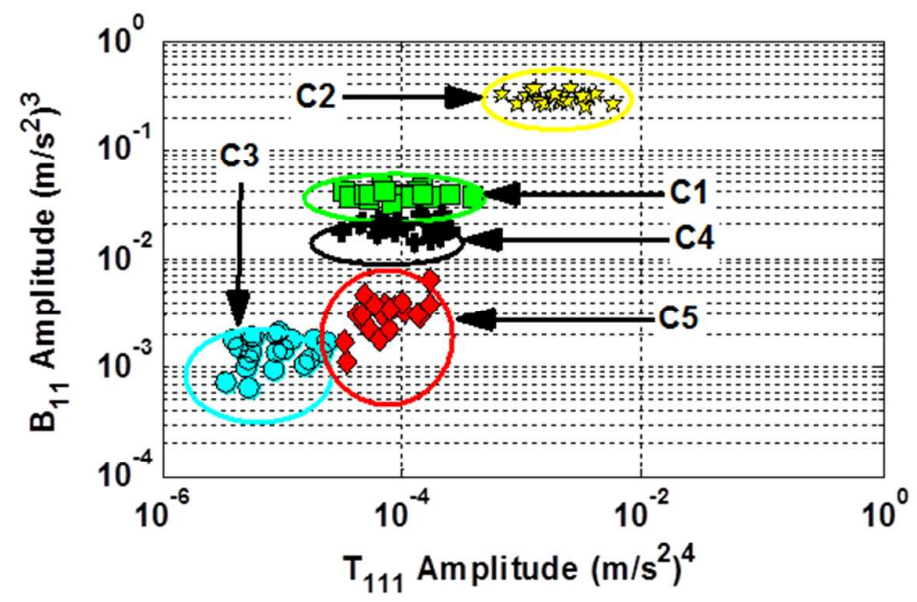

Figure 5 Typical combined magnitudes of $\mathrm{B}_{11} \mathrm{pCCB}$ and $\mathrm{T}_{111}$ pCCT components for all cases under ideal laboratory scenario $\left(\mathrm{LS}_{0}\right)$ of complete data 

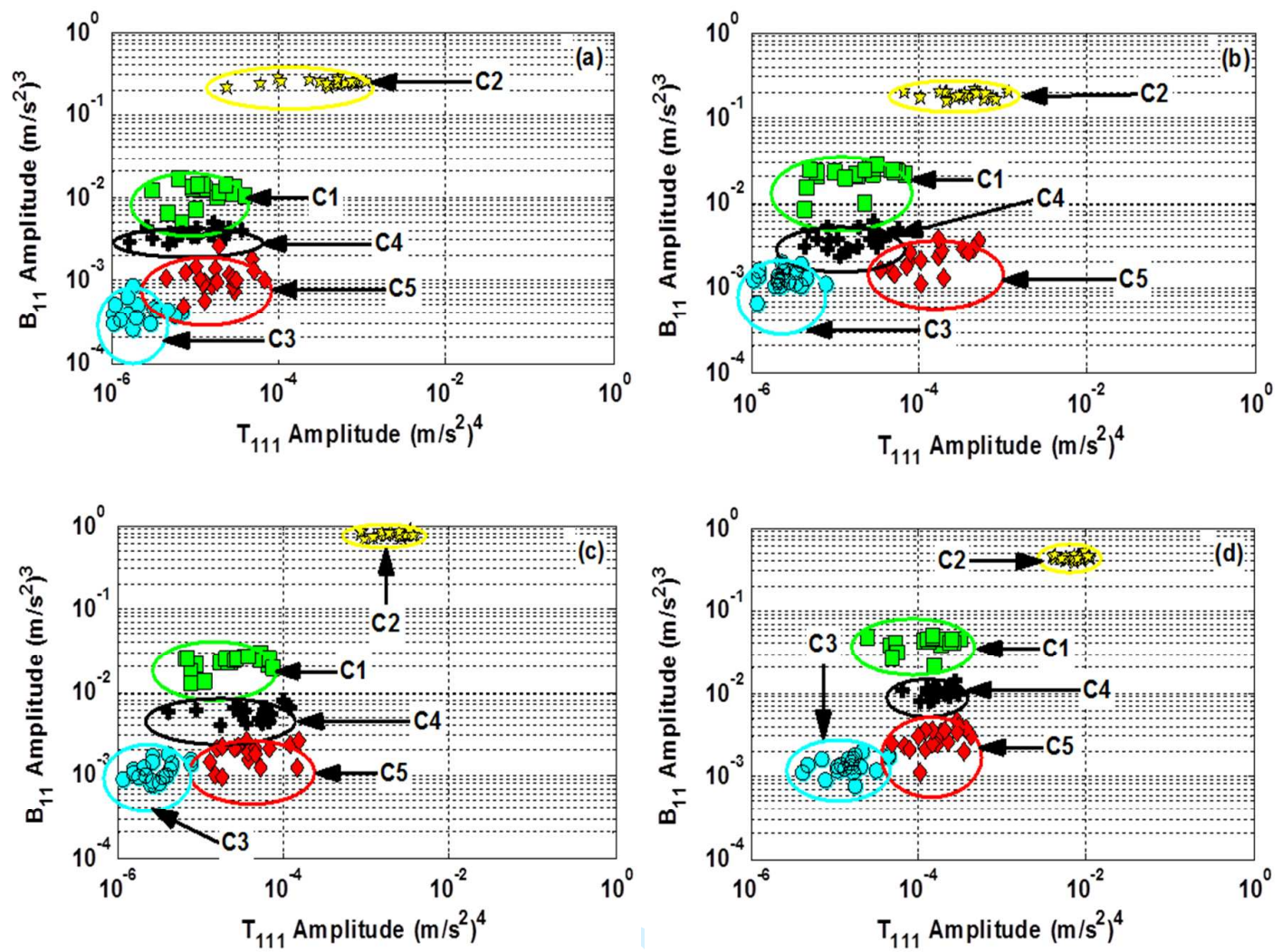

Figure 6 Typical combined magnitudes of $\mathrm{B}_{11}$ pCCB and $\mathrm{T}_{111}$ pCCT components for all cases under different laboratory scenarios of missing data (a) $\mathrm{LS}_{1}$ (b) $\mathrm{LS}_{2}$ (c) $\mathrm{LS}_{3}$ (d) $\mathrm{LS}_{4}$ 

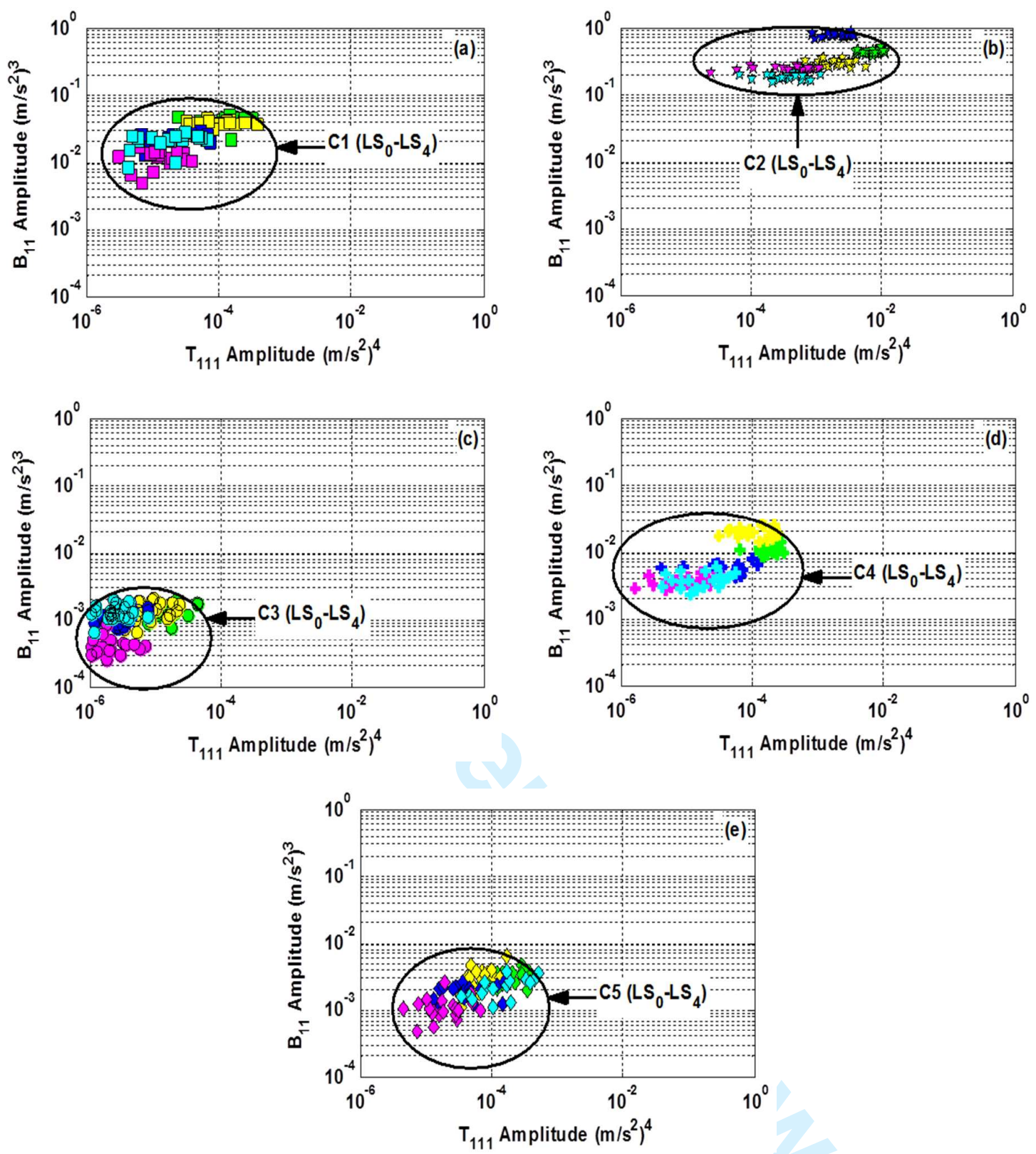

Figure 7 Typical combined magnitudes of $\mathrm{B}_{11}$ pCCB and $\mathrm{T}_{111}$ pCCT components for individual cases for all scenarios (a) $\mathrm{C} 1$ (b) $\mathrm{C} 2$ (c) $\mathrm{C} 3$ (d) $\mathrm{C} 4$ (e) $\mathrm{C} 5$ 


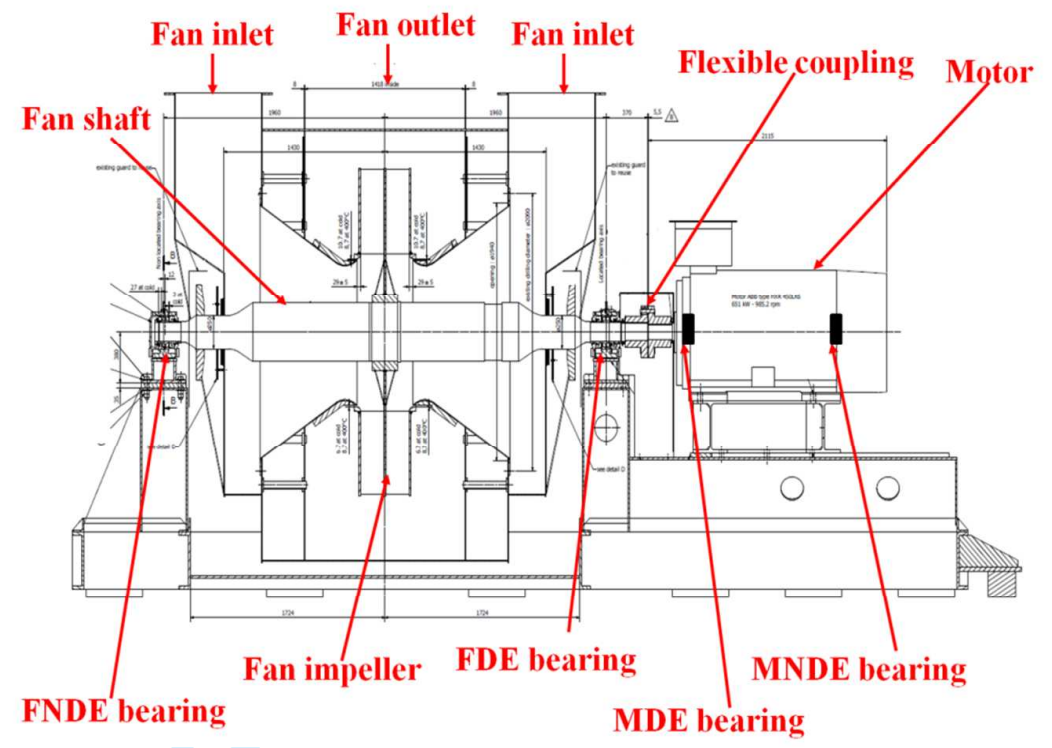

Figure 8 Schematic representation of RKIDF assembly [26] 


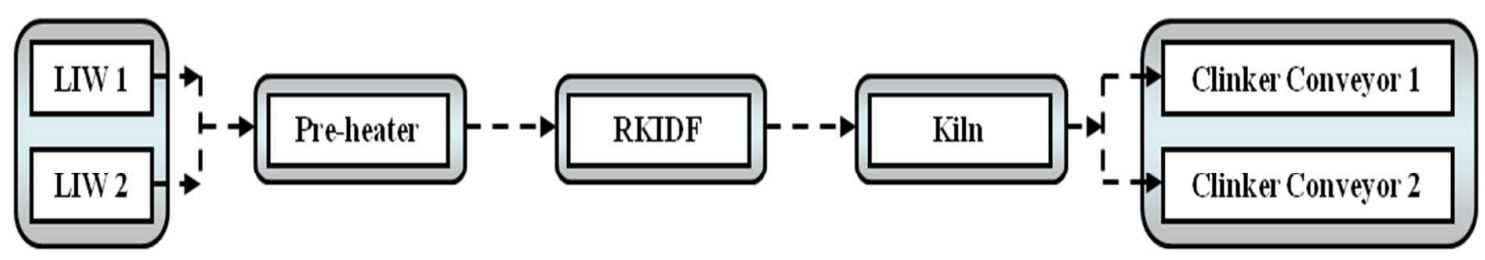

Figure 9 Schematic representation of the burning line 


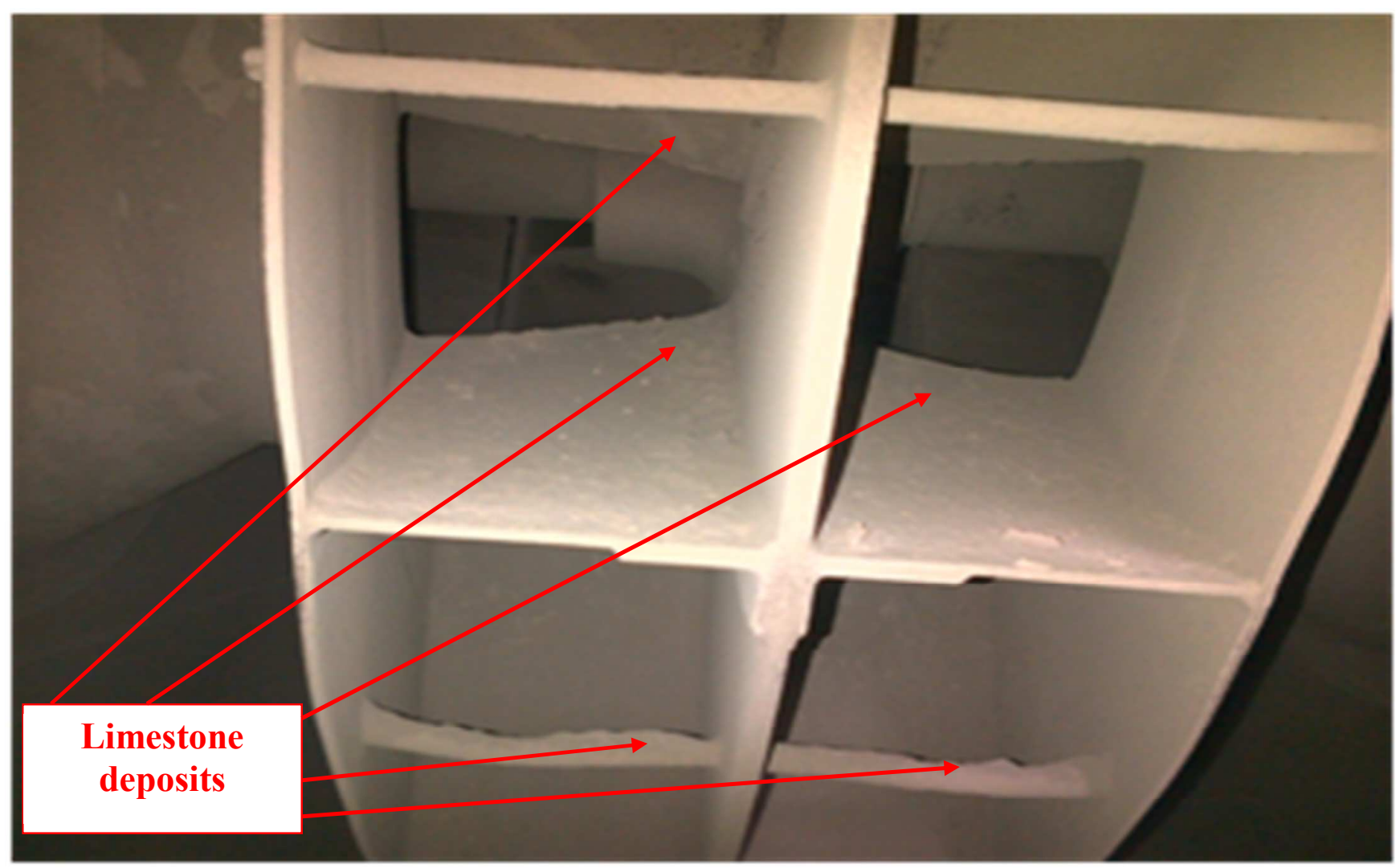

Figure 10 Limestone deposits on RKIDF impeller and blades [27] 


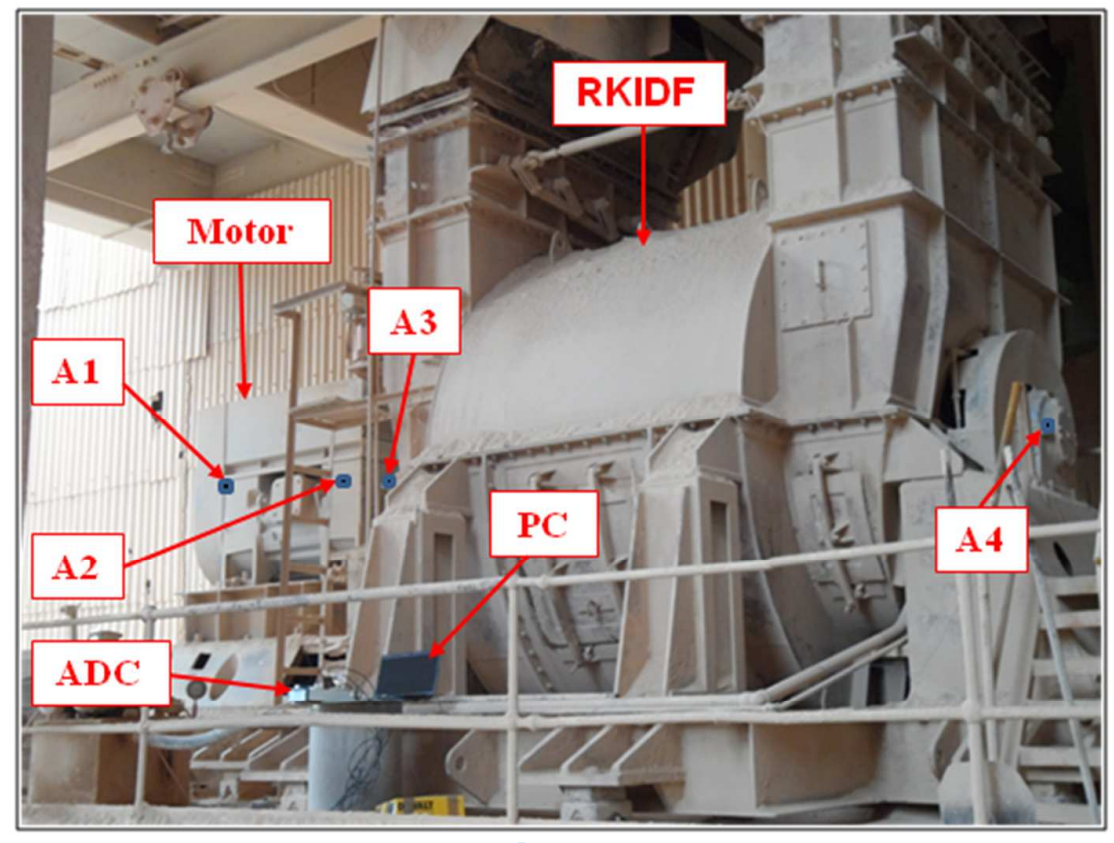

Figure 11 Photograph of on-site vibration measurement set-up [27] 

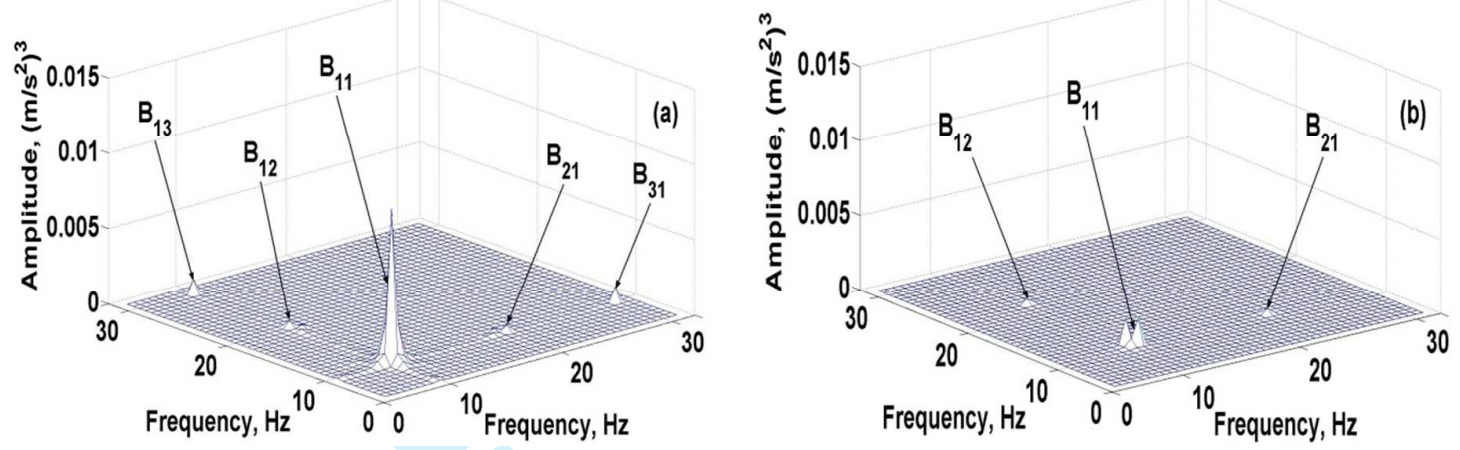

Figure 12 Typical pCCB plots (a) faulty (b) healthy 

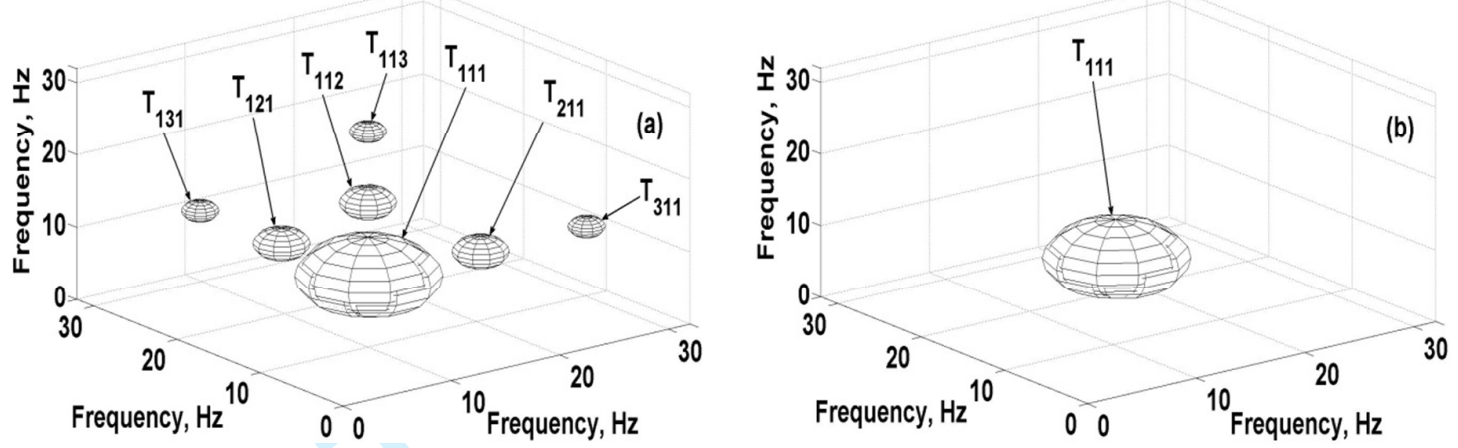

Figure 13 Typical pCCT plots (a) faulty (b) healthy 


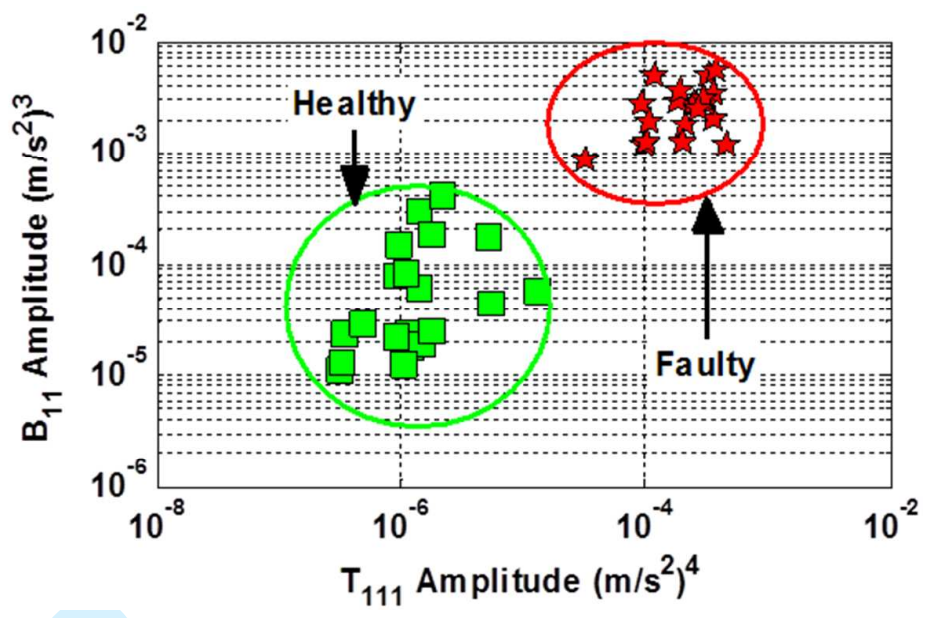

Figure 14 Typical combined magnitudes of $\mathrm{B}_{11} \mathrm{pCCB}$ and $\mathrm{T}_{111} \mathrm{pCCT}$ components for all cases under ideal industrial scenario $\left(\mathrm{IS}_{0}\right)$ of complete data 

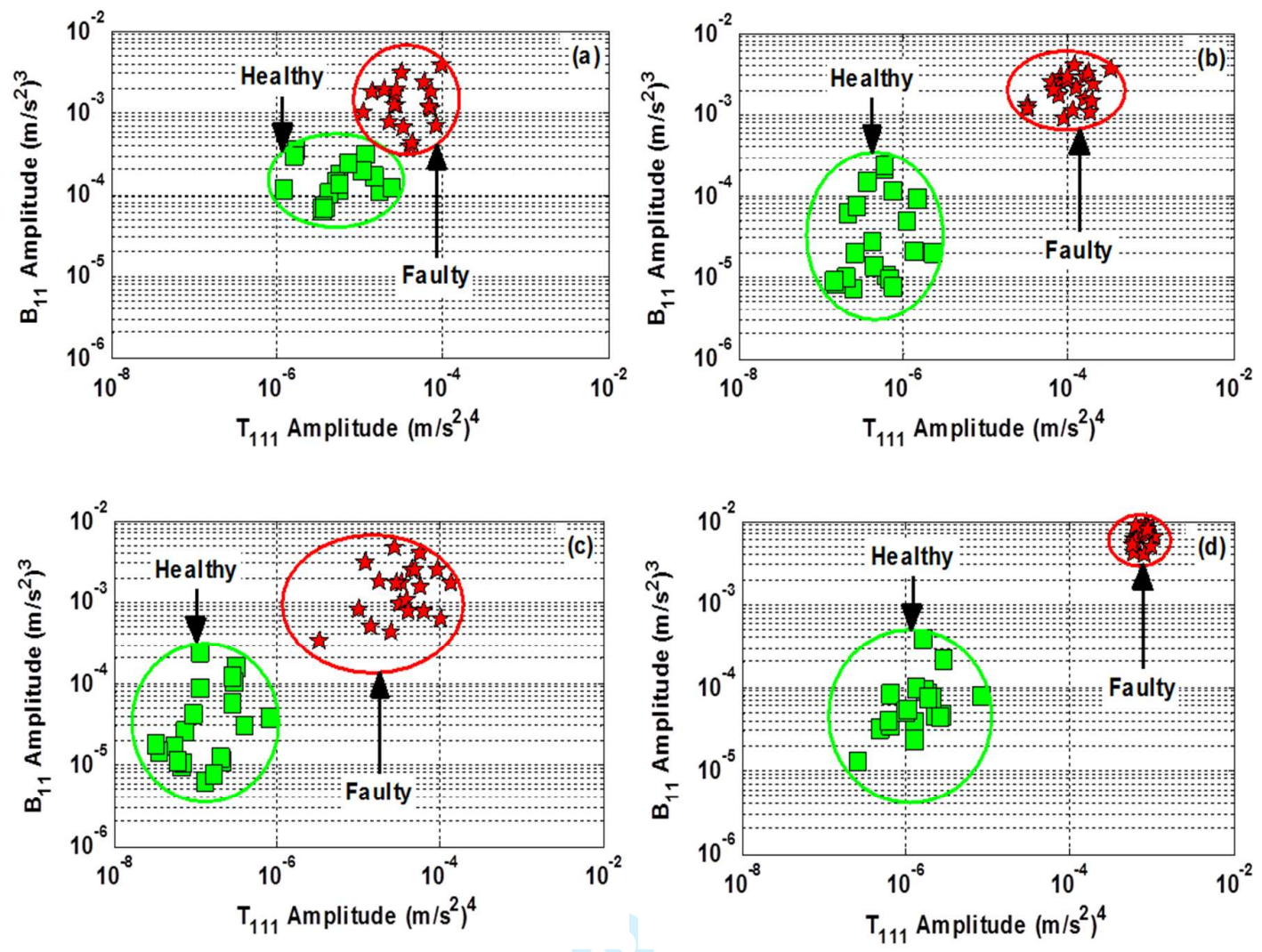

Figure 15 Typical combined magnitudes of $\mathrm{B}_{11} \mathrm{pCCB}$ and $\mathrm{T}_{111}$ pCCT components for all cases under different industrial scenarios of missing data (a) $\operatorname{IS}_{1}$ (b) $\operatorname{IS}_{2}$ (c) $\operatorname{IS}_{3}$ (d) $\mathrm{IS}_{4}$ 

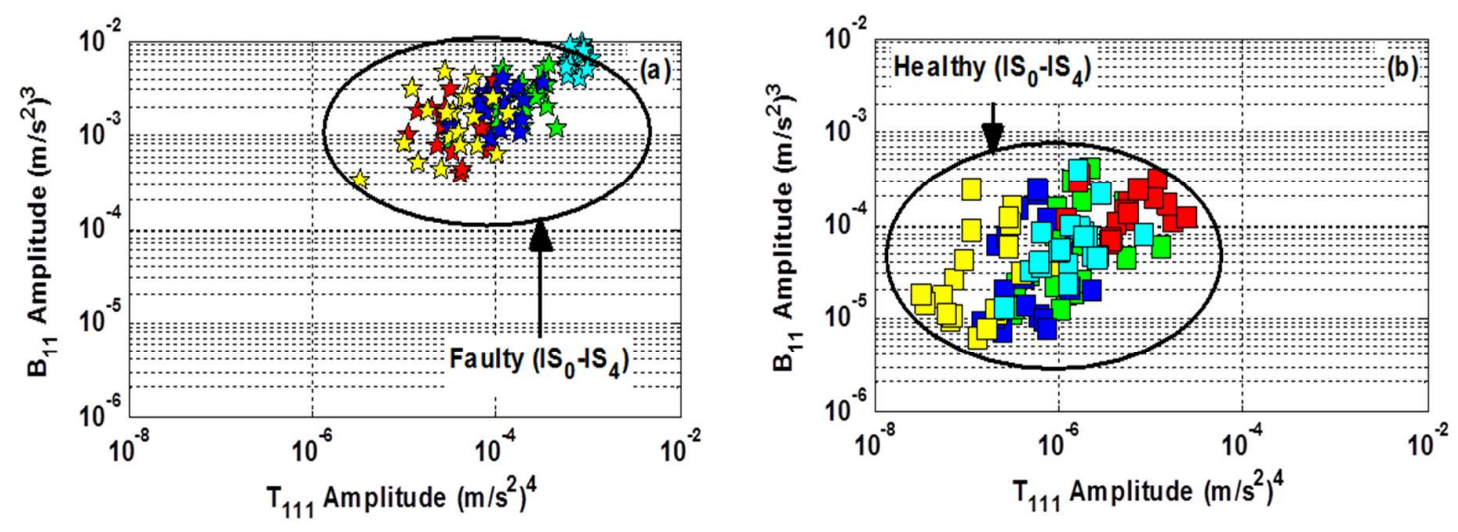

Figure 16 Typical combined magnitudes of $\mathrm{B}_{11} \mathrm{pCCB}$ and $\mathrm{T}_{111}$ pCCT components for individual cases for all scenarios (a) all faulty (b) all healthy 


\section{List of Tables}

Table 1 Experimental rig components and their specifications

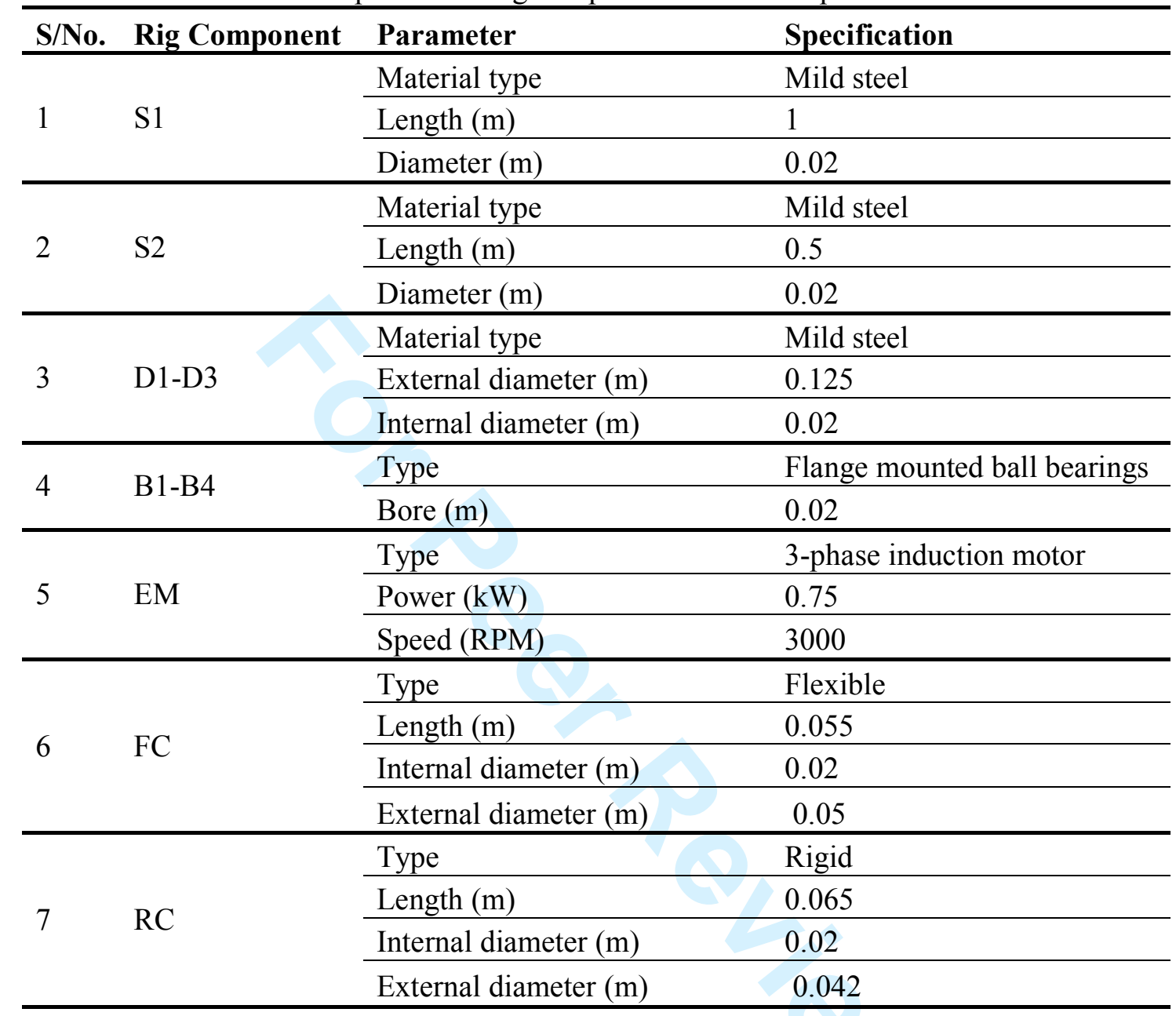


Table 2 Experimentally simulated cases [1]

\begin{tabular}{clcl}
\hline S/No. & Case & Abbreviation & \multicolumn{1}{c}{ Severity and Location } \\
\hline 1 & $\begin{array}{l}\text { Healthy with residual } \\
\text { misalignment }\end{array}$ & $\mathrm{C} 1$ & $\begin{array}{l}\text { Possible residual misalignment at } \\
\text { couplings (FC \& RC) }\end{array}$ \\
\hline 2 & Bent shaft & $\mathrm{C} 2$ & $\begin{array}{l}\text { 0.0034m axial run-out was created at } \\
\text { the centre of S1 }\end{array}$ \\
\hline 3 & Shaft misalignment & $\mathrm{C} 3$ & $\begin{array}{l}\text { 0.0004m mild steel shim beneath the } \\
\text { left-hand-side (LHS) of B1 foundation }\end{array}$ \\
\hline 4 & Shaft rub & $\mathrm{C} 4$ & $\begin{array}{l}\text { Rub using a brass sleeve of 0.021m on } \\
\text { S1, near D2 }\end{array}$ \\
\hline 5 & Cracked shaft & $\mathrm{C} 5$ & $\begin{array}{l}\text { 0.004m (depth) x 0.00025m (width) } \\
\text { crack on S1, at 0.16m from B1 }\end{array}$ \\
\hline
\end{tabular}


Table 3 Signal processing parameters for experimental data

\begin{tabular}{cll}
\hline S/No. & \multicolumn{2}{c}{ Signal Processing Parameter(s) } \\
\hline 1 & Sampling frequency & $10000 \mathrm{~Hz}$ \\
\hline 2 & Number of data points (N) & 8192 \\
\hline 3 & Frequency resolution $(\mathrm{d} f)$ & $1.2207 \mathrm{~Hz}$ \\
\hline 4 & Number of averages & 88 \\
\hline 5 & Segment overlap & $95 \%$ \\
\hline
\end{tabular}


Table 4 Description of laboratory scenarios

\begin{tabular}{cccc}
\hline Scenario(s) & Abbreviation & Accelerometers & Missing Data Location \\
\hline 1 & $\mathrm{LS}_{1}$ & 123 & Bearing 4 \\
\hline 2 & $\mathrm{LS}_{2}$ & 234 & Bearing 1 \\
\hline 3 & $\mathrm{LS}_{3}$ & 124 & Bearing 3 \\
\hline 4 & $\mathrm{LS}_{4}$ & 134 & Bearing 2
\end{tabular}

1

2

3

4

5

6

7

10

11

12

13

14

15

16

17

18

19

20

21

22

23

24

25

26

27

28

29

30

31

32

33

34

35

36

37

38

39

40

41

42

43

44

45

46

47

48

49

50

51

52

53

54

55

56

57

58

59

60 
Table 5 Technical specifications of RKIDF [26]

\begin{tabular}{cll}
\hline S/No. & Parameter & Specification \\
\hline 1 & Fan type & 105 type -12 double inlet \\
\hline 2 & Fan serial number & VW5/39231-02-01 \& 02-02 \\
\hline 3 & Fan shaft length $(\mathrm{m})$ & 4.65 \\
\hline 4 & Impeller diameter $(\mathrm{m})$ & 2.697 \\
\hline 5 & Fan weight $(\mathrm{kg})$ & 5350 \\
\hline 6 & Number of impeller blades & 11 \\
\hline 7 & Motor speed $(\mathrm{RPM})$ & 993 \\
\hline 8 & Power $(\mathrm{kW})$ & 656 \\
\hline 9 & Voltage $(\mathrm{V}) /$ current $(\mathrm{A}) /$ frequency $(\mathrm{Hz})$ & $690 / 674 / 50$ \\
\hline 10 & Fan bearings & Cooper self-aligning \\
\hline 11 & Motor bearings & Cooper self-aligning \\
\hline
\end{tabular}

